\title{
Affirmative Action and the Choice of Amends
}

\author{
George Hull
}

Received: 8 March 2014 / Revised: 16 July 2014 / Accepted: 2 October 2014 /

Published online: 25 October 2014

(C) The Author(s) 2014. This article is published with open access at Springerlink.com

\begin{abstract}
Affirmative action is often implemented as a way of making redress to victims of past injustices. But critics of this practice have launched a three-pronged assault against it. Firstly, they point out that beneficiaries of preferential policies tend not to benefit to the same extent as they were harmed by past injustices. Secondly, when its defenders point to the wider benefits of affirmative action (e.g. destruction of stereotypes, creation of role models), critics maintain that such ends could never be sufficiently weighty to permit violating equal treatment. And, thirdly, critics dispute whether the alleged benefits of affirmative action really ensue. I argue this threepronged assault is flawed at the conceptual level. Firstly, it operates with an impoverished conception of redress. When $\mathrm{X}$ wrongs $\mathrm{Y}, \mathrm{X}$ does not make exhaustive redress to $\mathrm{Y}$ by compensating $\mathrm{Y}$ for the harm $\mathrm{Y}$ suffered due to $\mathrm{X}$ 's wrong action. Redress also requires rectification of the wrong: $\mathrm{X}$ must put right the wrong done to $\mathrm{Y}$ by making adequate amends. While the means of compensation are determined by the extent of the harm for which compensation is due, the adequacy of amends for a wrong is less tightly controlled by the nature of the wrong. So, secondly, it is perfectly right that the choice of amends be informed by the prospect of wider benefits. Whether, thirdly, these benefits are in fact in prospect in the case of affirmative action is an empirical question which philosophy cannot answer.
\end{abstract}

Keywords Affirmative action · Redress · Rectification · Compensation · Harm · Wrong

"Affirmative action" has shifted in meaning over the years, ${ }^{1}$ and the phrase remains ambiguous, ${ }^{2}$ but the affirmative action I propose to defend takes the following form:

(A) An institution offering employment, education, training or contracts to selected applicants implements a policy of giving preference to those qualified applicants

\footnotetext{
${ }^{1}$ See Cohen 2003a, 12-20; Sterba 2003a, 191.

${ }^{2}$ See Goldman 1976, 193; Sterba 2003a, 199-200; Cohen 2003b, 279; Benatar 2008a, 275.

G. Hull $(\bowtie)$

Philosophy Department, University of Cape Town, Private Bag X3, Rondebosch 7701 Cape Town, South Africa

e-mail: george.hull@uct.ac.za
} 
who possess characteristic $C$, where characteristic $C$ does not render an applicant more qualified for the position, place or contract they apply for

(B) Either just (i) (below) or both (i) and (ii) (below) - but not (ii) alone-is true of the institution implementing such a policy

(i) The institution in question has, in the recent past, intentionally discriminated against those who possess characteristic $C$ in a way which constituted a serious injustice, and its current policy of preference is intended as a way of making redress for this serious injustice to those who possess characteristic $C$

(ii) The institution in question intends, by means of its current policy of preference, to increase the diversity with regard to possession or non-possession of characteristic $C$ of its body of workers, students, trainees or contractors, reasonably anticipating that this increase in $C$-diversity will benefit the institution itself, those who are professionally linked to the institution, or the wider community in which the institution in question is situated

Both (A) and (B) (above) must apply.

To be qualified for a place, position or contract, an applicant must be able to carry out adequately the tasks attached to that place, position or contract, or the recruiting or contracting institution must reasonably anticipate them to be. An applicant not able adequately to carry out these tasks, or whom the recruiting or contracting institution reasonably anticipates not to be, is unqualified. Among qualified applicants, an applicant who is able to carry out the tasks in question to a higher standard than another applicant is more qualified than that other applicant. Among unqualified applicants, an applicant who is able to carry out the tasks in question to a higher standard than another applicant is less unqualified than that other applicant.

A body of workers, students, trainees or contractors becomes more diverse with regard to the possession or non-possession of a given characteristic, the closer the ratio of possessors to non-possessors of that characteristic in the body in question comes to $1: 1$. The closer a body of workers, students, trainees or contractors comes to $100 \%$ possessors of a characteristic, or $100 \%$ non-possessors of it, the less diverse is the body in question with regard to the possession or nonpossession of that characteristic.

An institution intentionally discriminates against those who possess a given characteristic when it implements a policy of treating those who possess that characteristic differently from those who do not possess it, on the basis of their possession of the characteristic in question, and in a way which tends to harm or disadvantage them or which otherwise constitutes an injustice. It is possible for an institution intentionally to discriminate against those who possess a given characteristic without that constituting an injustice.

An institution may be articulated into a number of branches or subsidiaries at different levels of the institution's overall hierarchy, enjoying various degrees of autonomy. When this is the case, a branch or subsidiary at one level may implement a preferential policy in order to make redress for unjust discrimination perpetrated by itself, or by a different branch or subsidiary at the same level as it, or by a different branch or subsidiary at a different level to it, or by the institution as a whole. The institution as a whole may implement a preferential policy in order to make redress for 
unjust discrimination perpetrated by any branch or subsidiary at any level of its overall hierarchy, or by the institution as a whole.

Not every policy or programme which deserves the label "affirmative action" satisfies the above description. An institutional policy which gave preference even to unqualified candidates, for example, or a policy of preference implemented with the sole aim of reaping the benefits of diversity could also count as cases of affirmative action. Equally, a preferential policy intended by one institution to make redress to $C$ possessors for an injustice committed against them by a second institution, unconnected to the first, could count as affirmative action, as could a preferential policy intended to make redress for unjust, but not seriously unjust, discrimination, or for discrimination which, though unjust, was not intentional. Additional aims could, furthermore, replace or supplement (B) (i) and (ii), making a preferential policy affirmative action of a distinctive type. To create a more just society in the future could be one such aim, ${ }^{3}$ as could be to achieve a workforce or student body whose proportional possession of characteristic $C$ was in line with that of the national population. ${ }^{4}$ And sometimes affirmative action consists simply of steps taken by a recruiter or contractor to ensure that it does not discriminate unjustly against $C$-possessors, and to ensure that as many $C$-possessors as possible are aware of the places, positions or contracts it offers. ${ }^{5} \mathrm{I}$ do not propose to defend any of these further forms of affirmative action; but that does not imply I regard all of them as indefensible.

I do, though, regard as indefensible some cases of affirmative action which would satisfy the above description. For instance, the degree of preference an affirmative action programme gave to $C$-possessors might be greater than was warranted by the gravity of the injustice for which the preferential policy in question was intended as redress. The variety and extent of the benefits which could reasonably be expected to flow from a given preferential policy might also have a bearing on whether that preferential policy ought to be implemented. But factors under (B) (ii) and factors under $(B)$ (i) impact upon the normative status of preferential policies under $(A)$ in rather different ways, as I will explain shortly.

I must also explain in due course what it is for one party to make redress to another party for an injustice done by the former to the latter. But, as a preliminary approximation, to make redress to someone whom one has wronged is to make up for what one has done to them by doing something for them (for example, transferring goods or money to them, or performing or providing a service for them). I will not, on the other hand, specify under what conditions intentional discrimination against those who possess a given characteristic constitutes an injustice against those possessing that characteristic. It will be enough for the purposes of my argument to rely on consensus regarding various classes of case.

\footnotetext{
${ }^{3}$ For defences of this rationale for preferential policies see Dworkin 1976, 69, 74, 82; Dworkin 1977, 228, $232,239$.

${ }^{4}$ For critical discussions of this rationale for preferential policies see Cohen 2003b, 296; Benatar 2008a, 297299.

${ }^{5}$ Cohen $(2003 a, 40)$ advocates this form of affirmative action, calling it "outreach". Benatar (2008a, 275-277) calls it "equal opportunity affirmative action". Sterba (2003a, 204-205, 208-209) divides it into "outreach" and one form of "remedial affirmative action", though sometimes $(2003 \mathrm{a}, 277)$ he uses the phrase "outreach affirmative action" to refer to a combination of the two.
} 
What follows is chiefly a defence of affirmative action of the type I have specified. However, I will also make clear what sorts of consideration can mean that in certain circumstances it is not justified.

Although conceptually it is somewhat narrow, the type of affirmative action I am defending is instantiated by a large number of current and historical cases.

The United States of America and the Republic of South Africa - to take just the two most discussed examples - are states which have, in the recent past (well within living memory in both cases, in the South African case within a generation), discriminated against those inside their borders who were of particular ethnicities in a way which constituted a serious injustice.

In both the United States and South Africa legislation and judicial rulings emanating from various levels of the state, and enforced by the police and the army, intentionally placed special restrictions on the employment and education opportunities, ${ }^{6}$ freedom of movement, ${ }^{7}$ and voting rights ${ }^{8}$ of those who were of particular ethnicities.

Soon after acknowledging that they had discriminated unjustly against those who were of the ethnicities in question, these two states both implemented preferential policies intended to make redress to those of the ethnicities in question for this serious injustice.

These policies (still in place to differing degrees in both countries) were implemented by various levels of the state, and gave preference to those of the ethnicities in question who applied for a range of employment opportunities, education and training places, and government contracts. ${ }^{9}$

Besides stressing the necessity of making redress, both of these states, in order to justify their preferential policies, have appealed to the benefits, to local communities as well as to society as a whole, of increased diversity (with regard to being or not being of the ethnicities in question) in the bodies of workers, students, trainees or contractors affected by those policies.

Though these policies have largely been in line with the specification of affirmative action I gave earlier, it must be admitted they have sometimes contradicted it by abandoning the explicit aim of redress - and perhaps in other respects too. Moreover, they have at times pursued further aims on top of (B) (i) and (B) (ii), including that of approaching or achieving bodies of workers, students, trainees or contractors with an ethnic make-up in line with that of the national population. ${ }^{10}$ And, unsurprisingly, implementation has not always corresponded perfectly with declared policy. ${ }^{11}$

Much the same could also be said of many historical and current affirmative action policies implemented not by states but by other institutions, such as corporations and universities.

\footnotetext{
${ }^{6}$ On the South African Bantu Education Act of 1953 and its context, see Thompson 2000, 195-197; Bloch 2009, 43-45. On racial segregation of educational institutions in the U.S.A. see Jones 1995, 269.

${ }^{7}$ Thompson $(2000,191-195)$ and Gumede $(2007,19)$ explain South Africa's "homelands" and pass laws, and the Group Areas Act of 1950. On racial segregation in the U.S.A. up to the 1950s see Tindall \& Shi 1997, $1020-1024$.

${ }^{8}$ On South Africa's electoral system in the 1980s, see Thompson 2000, 225-226. On denial of the franchise to black people by the state in the American South as late as the 1960s, see Jones 1995, 536.

${ }^{9}$ See Jones 1995, 582; Sterba and James 2003a, b, 193-196.

${ }^{10}$ See Terreblanche 2012, 93-94; Cohen 2003a, 18-20.

${ }^{11}$ For critical discussions of the implementation of Black Economic Empowerment in South Africa, see Gumede 2007, 287-300; Mbeki 2009, 66-73; Terreblanche 2012, 93-100.
} 
The type of affirmative action I specified earlier faces a three-pronged assault, against which I mean to defend it:

(1) Wrong people

The first prong of the assault says that affirmative action of the type I have specified is generally an inept way of making redress for $C$-discrimination. The extent to which $C$-possessors benefit from a policy of $C$-preference will vary, some benefiting from it a lot, some less, and some not at all. The extent to which an individual $C$-possessor benefits from a preferential policy depends, not on how much that individual was harmed by unjust $C$-discrimination, but on whether they are qualified for the place, position or contract on offer, and on how qualified they are. This - says the first prong of the assault - is a systemic problem with affirmative action considered as a means of redress, because redress for unjust discrimination ought to be calibrated to make redress to individuals in proportion to how much unjust discrimination harmed them.

Unjust discrimination denies people opportunities they would otherwise have had. It prevents people from achieving what they otherwise would have - whether in education, in their career, or in other spheres including their personal life. These, among others, are real harms resulting from unjust discrimination, for which redress should be made by the perpetrator of the injustice.

This prong of the assault grants that the benefits of employment, education, training and contracts can constitute means of redress to people who have been unjustly discriminated against. That is because these benefits can make up for the harm such people suffered due to unjust discrimination.

However it points out that those who suffered most harm due to unjust discrimination were likely so disadvantaged by it that they are now either unqualified for the places, positions or contracts to be awarded preferentially, or so much less qualified than other qualified applicants that, even with preference, they will not obtain one of the places, positions or contracts in question. Meanwhile other people, who possess characteristic $C$, but who were not seriously - or even who were not at all - disadvantaged by unjust discrimination, will obtain the preferentially awarded places, positions or contracts.

This prong of the assault concludes that affirmative action of the type specified earlier is an especially inept way of making redress for unjust discrimination, because, in general, it benefits individual $C$-possessors more, the less those individuals were harmed by unjust discrimination. $C$-possessors whom unjust discrimination harmed most it does not benefit at all. And it unjustifiably gives preference to $C$-possessors whom unjust discrimination did not harm at all. ${ }^{12}$

According to this prong of the assault, (B) (i) is generally not sufficient to render (A) justifiable.

\footnotetext{
${ }^{12}$ For "wrong people" arguments against various affirmative action programmes, and affirmative action in general, see Simon 1974, 43-45; Goldman and Alan 1975, 36-37; Sher 1975, 51-60; Goldman 1976, 204 205; Cohen 2003a, 26-33; Cohen 2003b, 299-300; Pojman 2007, 475-476; Benatar 2008a, 282-284; Benatar $2012,217$.
} 
(2) No benefits

The second prong of the assault denies that an increase in diversity with regard to possession or non-possession of particular characteristics which do not count as qualifications can reasonably be expected to bring benefits to a particular institution implementing a preferential policy, those who are professionally linked to that institution, or the wider community.

This prong of the assault takes different forms, depending what characteristic it is possession of which wins an individual preference in a given case of affirmative action, and depending what type of institution is implementing the preferential policy.

Depending on the nature of the case of affirmative action in question, this prong of the assault will sometimes claim that no benefits at all can reasonably be expected from the increase in diversity it gives rise to; sometimes, though, it will limit itself to the claim that no net benefits can reasonably be expected from the increase in diversity it gives rise to.

It need not commit itself to saying that no benefits (or no net benefits) can ever reasonably be expected from an increase in diversity with regard to characteristic $C$; rather, it could say merely that no benefits (or no net benefits) can reasonably be expected from an increase in diversity with regard to $C$-diversity which comes about, or is thought to come about, because of a policy of giving preference to $C$ possessors. $^{13}$

This prong of the assault, by denying that it is reasonable to expect a preferential policy to produce benefits, denies that (B) (ii) will in fact add to the justifiability of $(A)$.

(3) Wrong reasons

The third prong of the assault says that, even if (contrary to the second prong) an increase in $C$-diversity could reasonably be expected to have good consequences, this fact could never justify - whether alone, or in conjunction with an intention to make redress for unjust discrimination - a policy of preference on the part of the recruiting or contracting institution in question, nor could it legitimately influence the nature of a preferential policy which was (contrary to the first prong) justified solely by the intention to make redress for unjust discrimination.

This prong of the assault does not (like the second prong) deny that the increase in diversity effected by policies of preference is beneficial. Rather, it denies that preferential policies are acceptable means for achieving the benefits alleged to flow from diversity. The prospect of those benefits, says this prong of the assault, could not cancel or override the injustice of a policy which discriminates against those non- $C$-possessors (and in favour of $C$-possessors) who apply for the places, positions or contracts on offer.

This prong of the assault need not say that such a discriminatory policy could never be justifiable. It might even accept (unlike the first prong) that the intention to make redress for unjust discrimination could render such a policy justifiable. However, if that were the case, then how much preference was shown to whom

\footnotetext{
${ }^{13}$ Cohen (2003a, 109-180) gives a "no benefits" argument against race-preference affirmative action. Benatar (2008a, 288-297, 302-304) gives what amounts to a "no benefits" argument against affirmative action in South Africa.
} 
ought to be determined solely by the amount of harm current applicants had experienced due to the unjust discrimination in question. The beneficial consequences to be expected would have no role to play either in justifying or in shaping the preferential policy in this case. ${ }^{14}$

By denying that any anticipated benefits of diversity could provide legitimate reasons for implementing a preferential policy or designing such a policy in a specific way, this prong of the assault denies that (B) (ii) could conceivably add to the justifiability of $(A)$.

I will defend the type of affirmative action I have specified against the first prong, and then against the third prong, of the assault it has faced, after which I will go on to discuss briefly the second prong of the assault. As will emerge in what I say, there is a greater need for empirical research to assess the second prong's claims than to assess those of the first and third prongs.

When one party, $X$, has wronged another party, $Y, X$ ought to make redress to $Y$. The three-pronged assault on affirmative action has no quarrel with this principle.

But we can distinguish two different sorts of redress, both of which might be owed by $X$ to $Y$ :

Compensation. When $X$ wrongs $Y$, it will often be the case that $X$ 's wrong action harms $Y$. The wrong done by $X$ to $Y$, that is to say, will often cause a reduction in $Y$ 's overall welfare. This reduction may be capturable in straightforwardly quantitative terms, particularly if the harm is a financial loss or a loss of property which $Y$ was retaining solely for purposes of sale or exchange. But the reduction may not be fully capturable in quantitative terms, needing also to be understood as the loss of a qualitative aspect of $Y$ 's welfare- $Y$ 's sense of hearing, for example, or various mental capacities. In either case, the harm in question generally could have come about without $Y$ 's having been wronged at all, let alone wronged by $X$ : $Y$ could have suffered the harm solely through their own fecklessness, say, or solely due to a natural disaster no one could have predicted. In either case it makes a significant difference when $Y$ suffers the harm not through one of these other causes, but because of a wrong done to them by $X$. When a wrong done by $X$ to $Y$ causes a reduction in $Y$ 's overall welfare, $X$ ought to take action to restore $Y$ 's welfare to what it would have been had $X$ 's wrong action never impacted adversely upon it. ${ }^{15}$ When $X$ wrongs $Y$ in a way which harms $Y$, that is to say, $X$ ought to give compensation to $Y$ for the harm done.

It would, of course, often be impossible for $X$ to compensate $Y$ fully for the harm $X$ 's wrong action caused them. When this is the case, $X$ might sometimes be excused from providing full compensation to $Y$, as they also might when it is only through an extraordinary sacrifice on $X$ 's part that they could provide full compensation to $Y$. But

\footnotetext{
${ }^{14}$ For "wrong reasons" arguments against preferential policies see Cohen 2003a, 39-40, 94; Pojman 2007, 406-407. Benatar (2008a, 292) is offering a "wrong reasons" argument when he writes, 'I think that an equality of opportunity principle trumps the effect that an admission or hiring policy has on people's prejudices. Prejudices and stereotypes have to be dealt with in other ways that do not treat people unjustly.'

${ }^{15}$ Nozick $(1974,57-58)$ discusses some of what would be required for a fuller specification of this basic principle.
} 
it is not necessary to discuss the normative upshot of all such mitigating circumstances in order to make clear what sort of redress is constituted by compensation.

Rectification. Compensation is not the only sort of redress. I will introduce eight considerations which, taken together, amount to a case for thinking that another type of redress - rectification, or making amends - is both possible and, at least in the case of a serious wrong, required of the perpetrator of that wrong.

(a) If a wrong action causes no harm to the victim, then the perpetrator of the wrong action cannot give compensation to the victim. Where there is no harm, there can be no compensation. But in cases of such harmless wrongs, at least when the wrong is serious, it does not seem impossible for the perpetrator to make redress to the victim.

$X$, a doctor, might maliciously administer what they took to be an overdose of a medicine to rid themselves of their patient, $Y$, but, far from killing $Y$, inadvertently cure $Y$ of a debilitating disease with the dosage. ${ }^{16}$ In this case, it is clear that, though $X$ has wronged $Y$ (by trying to murder them), $X$ has not just done no harm to $Y$, but substantially increased $Y$ 's overall welfare. (Let us imagine that any shock and distress $Y$ feels are negligible in comparison with their joy at recovering from the disease.) Consequently, $X$ cannot compensate $Y$ for any harm caused. Nonetheless, $X$, remorseful for the deed which he now acknowledges to have been gravely wrong, might later approach $Y$ and offer to pay the medical bills of $Y$ and $Y$ 's family for the rest of $X$ 's life. Depending on $X$ 's motives, it could surely be right to interpret this act as a form of redress - as $X$ 's making amends to $Y$ for what $X$ did.

(b) Moreover, it is not mysterious at the conceptual level why redress should not be exhausted by compensation. If, as I suggested earlier, we think of redress as making up for something, then what compensation makes up for is harm. That is why there is the possibility of giving compensation to somebody who has not been wronged by anyone-if the state undertakes to compensate victims of natural disasters, for instance. ${ }^{17}$ As the discussion of compensation above and the malicious doctor case in (a) (above) together show, harming and wronging can come apart completely; but, even when they don't, the fact that one's action has harmed someone is conceptually distinct from the fact that one has wronged them. Consequently, there is conceptual space for a sort of redress which makes up, not for harm, but for a wrong.

(c) Still, it might seem mysterious how a transfer of goods or money, or a promise to provide services, could constitute redress for a wrong (as $X$ 's offer to $Y$ in (a) surely does). In comparison it is relatively easy to understand how compensation works - if the harm suffered was the loss of $£ 800$, compensation can take the form of a transfer of $£ 800$; if the harm was reduced hearing, compensation can take the form of a state-of-the-art hearing aid, complete with a life supply of batteries. But a clue is given to us in the fact that the remorseful doctor, $X$, could explain to the victim, $Y$, the intention behind their offer by saying they are making it "as a way of

\footnotetext{
16 This example is taken from Bovens 2008 (222).

${ }^{17}$ See Boxill 1972, 108-109, for a discussion of this kind of compensation. He reserves the term "reparation" for compensation owed by one person to another because the former has behaved unjustly towards the latter.
} 
saying sorry", or "to say sorry". These locutions suggest a constitutive link between the non-compensatory sort of redress (rectification) and the practice of apologising. Following this up will shed light on the common intuition that in cases of serious wrongdoing a merely verbal apology is not enough, and some apologetic action is required from the perpetrator.

(d) But this linguistic lead might be thought to deepen, rather than clear up, the mystery. After all, a sincere apology expresses not just cognitive recognition of the fact that what one did was wrong, but also remorse for the deed in question and the resolve not to behave in such a way in the future. ${ }^{18}$ It may, on the face of it, appear implausible that a transfer of goods or services could go any way towards performing such expressive functions.

However, considering the phenomenon of gift-giving ought to dissipate that initial impression. Giving someone a gift is a very familiar example of how the transfer of goods or services from one party to another can itself be expressive of the former party's feelings and intentions with regard to their relationship with the latter party. ${ }^{19}$ In interpersonal relations gifts often have a symbolic aspect which goes beyond simply choosing one of the goods or services which we know the recipient generally likes. ${ }^{20}$ For example, friends often choose gifts for each other which, through their associations, commemorate shared experiences, conversations or running jokes that have been significant in their ongoing relationship. In such cases one person's giving a gift to another can itself be an expression of the significance of a relationship to them and their commitment to its continuation. $^{21}$

We need to look into the possibility that a rectificatory transfer of goods or services might have a symbolic aspect, analogous to that of a gift, which enables it to perform some of the expressive functions of an apology. This would mean rectification operated in a very different way to compensation, the ideal type of which is a straight swap-a welfare gain straightforwardly substituting for a previous welfare loss.

(e) That should not be taken to imply that the question "How much?" is irrelevant when we are assessing the adequacy of a rectificatory transfer. One way in which it is relevant finds its parallel in gifts which are given, at least partly, as proof of sincerity and seriousness - "to show I mean it". Just as a gift we have taken trouble over (by making it ourselves, for instance, or simply by spending a lot of money) can be offered as proof that a verbal expression of, for example, love or gratitude is genuine, so goods or services which are particularly substantial, or

\footnotetext{
${ }^{18}$ Davis (2002, 170-171) argues that a "Consummate Apology" involves a "doxastic element", an "affective element" and a "dispositional element". Bovens (2008, 220), similarly, identifies a "cognitive component", an "affective component" and a "conative component" to a "genuine apology".

${ }^{19}$ Sandel $(2012,101)$ gives the example that '[g]iving, especially attentive giving, can be an expression of [love]'.

${ }^{20}$ This is why it is wrong to think that money is always the best gift, as Sandel $(2012,98-104)$ explains.

${ }^{21}$ Sandel $(2012,101)$ writes: 'On the expressive account, a good gift not only aims to please, in the sense of satisfying the consumer preferences of the recipient. It also engages and connects with the recipient, in a way that reflects a certain intimacy. This is why thoughtfulness matters.'
} 
have cost us a lot of trouble, can be offered as proof that a verbal apology is sincere and that this is a matter we take seriously. ${ }^{22}$

(f) But this is not the only way in which rectification can be apt, or fitting. The relationship between making amends and apologising can be more intimate - as locutions like "as a way of saying sorry" suggest. I have already mentioned that one thing a sincere apology expresses is remorse for one's wrong action. Remorse consists not just of self-reproach, but also of an inevitably frustrated will to undo one's past deed-literally to right the wrong. Making amends does not enable one to do the impossible, but one way in which the choice of amends can be apt is by expressing symbolically this frustrated will. If a perpetrator's wrong action was motivated by malice, they may endeavour to make amends with an act which is the act of a benevolent person, thereby negating, as it were, the will behind their past action with an opposite will in the present. ${ }^{23}$ Arguably the amends made by the doctor, $X$, in (a) (above) are fitting in an even more finely-tuned way, because the wrong perpetrated against $Y$ was to try to murder $Y$, and $X$ makes amends for it by offering, far from terminating $Y$ 's life, to endeavour to prolong and increase the quality of that life as best they can for the rest of $X$ 's own life.

(g) In many (but not all) cases it is important for a perpetrator's apology to their victim to be made publicly. This is true particularly when the wrong action is known of, or was observed by, many people (for example, a public humiliation). In such cases the "opposite"-ness of fitting amends - their tendency symbolically to "negate" the wrong action - can do more than express the perpetrator's remorse. It can also-like a public apology-perform the communicative function of confirming the victim's moral status, which the perpetrator's wrong action implicitly called into question. If $X$ wrongs $Y$ by, for example, breaking into $Y$ 's home and stealing $Y$ 's possessions, then $X$ treats $Y$ as though $Y$ did not have a right to be unmolested in their home and did not have a right to control over their possessions. But this implicit denial of $Y$ 's moral status should not be allowed to stand. One way in which it can be, so to speak, overturned is if $X$ is publicly punished for their violation of $Y$ 's rights. ${ }^{24}$ But another way (sometimes both may be necessary) is if $X$ publicly apologises to $Y$ and, as part of that apology, publicly makes amends to $Y$ which are fitting in the way outlined in (f) (above).

(h) Both punishment and the making of amends can be thought of as restoring the moral status quo ante. We have just seen one way they can do this: by publicly confirming the moral status of the victim, which the perpetrator's wrong action

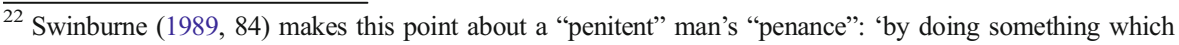
costs him time, effort, and money, he constitutes that act as a meant and serious act. To give what we cannot too easily afford is always a serious act. The penitent constitutes his apology as serious by making it costly'.

${ }^{23}$ Swinburne $(1989,83)$ writes: 'An agent cannot alter the fact that he did the past act, but what he can do is make the present 'he' in his attitude as different as possible from the past 'he' who did the act; that is the most he can do towards undoing the act.' Bovens $(2008,226)$ writes: 'A remorseful person wishes that she could do things over again. But the past cannot be undone, and the next best thing is to make amends. In making amends we are attentive to the victim's needs, and in doing so we try to distance ourselves from our past agency.' A seminar discussion of unpublished work by Madeleine Hayenhjelm also helped me to think through this aspect of rectification.

${ }^{24}$ See Wolff 2011, 125.
} 
implicitly called into question. Another way they can do this is by returning the moral status of the perpetrator to what it was before they wronged the victim. When $X$ wrongs $Y, X$, the wrongdoer, becomes less deserving of ordinary moral consideration, in particular on the part of $Y$ and $Y$ 's associates. ${ }^{25}$ However, when $X$ has been adequately punished for their wrong action against $Y$ (whether by $Y$ or $Y$ 's associates, or by another agency, such as the state), this is no longer the case. In particular, once $X$ has been adequately punished it is no longer legitimate for $Y$ or $Y$ 's associates to take revenge on $X$. The same applies when $X$ has apologised to $Y$ and, as part of that apology, made fitting amends to $Y$-but in this case with the proviso that $X$ 's apology and offer of amends need to have been accepted by the victim, $Y$. (Alternatively, $Y$ could accept $X$ 's verbal apology and turn down the offer of amends as superfluous.) A perpetrator who apologises and, as part of that apology, offers amends to their victim therefore puts it to some extent in the hands of the victim to determine their (the perpetrator's) moral status ${ }^{26}$ - though there are surely limits on a victim's discretion to reject a sincere apology, or to turn down the amends offered as insufficient.

I have given a reasonably full account of rectification, as I think the structure of this sort of redress is more complicated than that of compensation, and less well understood (even though making amends for what we have done is, as I have suggested, a widespread and recognisable type of activity). It would, of course, be possible to agree that this additional sort of redress, separate from compensation, exists, without agreeing with everything I have said about how rectification operates; and not all of what I say in what follows will depend on rectification functioning exactly as I have proposed it does. But one important consequence of the picture of rectification I have put forward is that the choice of amends to make for a wrong is somewhat more open-ended than the choice of how a victim is to be compensated. As I outlined above, if $X$ has wronged $Y$, then the compensation $X$ owes to $Y$ is very tightly controlled by the nature and extent of the harm $X$ 's wrong action caused to $Y$. The amends $X$ needs to make to $Y$, on the other hand, are controlled by the expressive and status-restoring functions of a sincere apology, and by the nature of $X$ 's wrong action. So the choice of amends is by no means entirely open-ended. However, just as with gift-giving there will normally be a large number of potential gifts which could fulfil the expressive functions required in a particular case, so with amends-making there will normally be many different ways in which the constraints arising from the functions of an apology and the nature of the perpetrator's wrong action might be met. This is why when choosing how to make amends, as when choosing a gift, there is room for creativity - even a kind of poetry. While compensation is blandly predictable, a particularly fitting gift or a surprisingly apt way of making amends can be the stuff of anecdote.

If the redress owed by perpetrators of unjust discrimination to those they discriminated against were limited to compensation, the first prong of the assault on affirmative action ("wrong people") would be very compelling.

\footnotetext{
${ }^{25}$ Bovens (2009, 230-231) discusses the nature of a wrongdoer's "loss of moral stature" in more detail.

${ }^{26}$ Bovens $(2008,233)$ writes: 'In accepting an apology, the victim awards the offender the status of a moral equal again, that is, a subject to whom respect is due on grounds of his personhood.'
} 
It should, however, first be admitted that the beneficiaries of many affirmative action programmes are to a large extent people who did suffer harm because of the injustice for which the affirmative action programme is meant as redress. Moreover, neither the fact that many who were harmed by discrimination do not benefit from affirmative action at all, nor the fact that many who benefit from affirmative action are benefited less than they were harmed by discrimination, constitute decisive objections to affirmative action as a method of compensation. This is because there is no reason why an affirmative action programme should be an institution's only method of compensating people it has discriminated against: it could be introduced in conjunction with other methods of compensation (such as cash payments) for those not fully compensated, or not compensated at all, by the affirmative action programme. In addition, it will in some cases be reasonable to expect that those who were harmed by the unjust discrimination but do not directly benefit, or do not directly benefit enough, from the affirmative action programme will nonetheless benefit indirectly from it - for example, through a family member's using their increased income to benefit them.

Nonetheless, it is certainly true that affirmative action programmes usually benefit at least some people who were not harmed at all by the relevant unjust discrimination, and often bestow benefits on people who were harmed by the discrimination which are much greater than the harm they suffered due to discrimination. These are serious problems with affirmative action, insofar as it is considered exclusively as a method of compensating those who were harmed by unjust discrimination.

However, to conclude that affirmative action is an inept way of making redress for unjust discrimination, as the first prong of the assault on affirmative action does, it would be necessary to rule out the possibility that affirmative action is an adequate way of making amends for unjust discrimination. That is to say, even though affirmative action might be the wrong policy to choose if all an institution needed to do was make up for the harm suffered because of its unjust discrimination, it might still be a perfectly good way of making up for the wrong of discriminating unjustly. In fact, to be defensible as a method of making redress, all that must be shown of a given affirmative action programme is that it goes some way towards compensating those who are owed compensation or that it goes some way towards making amends to those to whom amends are due - or both — without directly benefiting people to whom neither compensation nor rectification are due, or directly benefiting people to whom they are due, but to an extent which exceeds what is due to them on both counts. Affirmative action need neither be the only way in which an institution makes amends for discriminating unjustly, nor the only way in which an institution compensates victims of its unjust discrimination for the harm they suffered.

The question to whom redress should be made receives a different answer depending whether the redress in question is compensatory or rectificatory. That is because, as we have seen, it is possible to wrong somebody without harming them, and, consequently, at least when the wrong was serious, it can be the case that one should make amends to some person to whom one owes no compensation whatsoever.

When an institution implements a policy of discriminating against $C$-possessors in a way which constitutes a serious injustice, it is not only to those $C$-possessors who suffered harm as a result of this serious injustice that the institution should make amends. For example, when a state enacts a law applying to all its citizens which unjustly discriminates against $C$-possessors, the enactment of that law is an injustice 
against all $C$-possessors who are citizens of that state. In some cases, it is, admittedly, harder to delimit with precision who is wronged by a discriminatory policy. For instance, if a corporation based in London adopted a hiring policy which was unjustly discriminatory against $C$-possessors, it would seem too narrow to say that adopting this policy wronged only those $C$-possessors who actually applied for a job while the policy was in place; on the other hand, it is surely too broad to say it wronged all $C$-possessors that exist.

In many cases the exact extent of amends which it is appropriate to make will depend on the answer to complex problems in theoretical ethics which I cannot resolve here. For example, if it is not possible to wrong someone who does not yet exist, then it could not be appropriate for a state to make amends for its discriminatory laws to anyone who was born after those laws were revoked. (It might, though, be necessary for that state to compensate some people born after the discriminatory laws were revoked, if they have been harmed as a result of them.) If, on the other hand, it is possible to wrong someone who does not yet exist, then people born after the discriminatory laws were revoked could also be among those to whom amends are due.

But one does not need to settle all controversies about the extent of those wronged in particular cases of unjust discrimination to see that the first prong of the assault on affirmative action is wrong to assume redress should only be made to those who suffered harm as a result of unjust discrimination. Because discrimination can be a harmless wrong, it is reasonable to expect that rectificatory redress for a given case of unjust discrimination will be due to more people than are owed compensation.

Now let us consider whether affirmative action can constitute adequate rectification for unjust discrimination.

It is clear that, considered as a way of making amends for unjust discrimination, affirmative action has the quality of "opposite"-ness which we saw is characteristic of rectificatory acts. Unjust discrimination tends to disadvantage or exclude people in respect to various goods and opportunities. Affirmative action, by contrast, involves giving people a relative advantage in respect to goods and opportunities. This makes affirmative action well suited to performing the expressive and communicative functions described in $(f)$ and ( $g$ ) (above). When accompanied by a sincere verbal apology, the introduction of an affirmative action programme for $C$-possessors can fittingly express remorse for - by symbolically "negating"- the wrong of discriminating unjustly against $C$-possessors in the past. Unjust discrimination by institutions, especially states, is often widely known of. The public introduction of an affirmative action programme for $C$-possessors, accompanied by a sincere verbal apology, can be an effective way of publicly confirming the moral status of $C$-possessors, which the institution's discrimination implicitly called into question. ${ }^{27}$

Compensatory redress, which makes up for harm, should benefit a victim to the same degree as the wrong committed against them caused them harm. But that is not true of rectificatory redress, which makes up for a wrong, since the same wrong can cause different amounts of harm (including none at all) in different instances. So, if a policy of affirmative action is introduced as rectificatory redress for unjust

\footnotetext{
${ }^{27}$ Hill (1991, 187-189) has also argued that affirmative action can be justified partly because of its expressive or communicative functions - its "message". However, he does not note the constitutive link between such functions and rectificatory redress, which I think weakens his case.
} 
discrimination, it is not an effective objection to point out, as the first prong of the assault on affirmative action does, that affirmative action does not benefit people in proportion to how much harm unjust discrimination caused them.

One might assume that rectificatory redress should benefit a victim in proportion, not to how much they were harmed, but to how serious the wrong committed against them was, and thus expect that victims of the same discriminatory policy ought to receive the same amount of rectificatory redress. However, the assumption behind this expectation is flawed, because compensation and rectification differ not just in what they make up for, but also in how they make up for it. Paradigm cases of compensation have, as I discussed earlier, the character of a straight swap- $x$ amount of harm being made up for with $x$ amount of benefit. But rectification, as we saw, makes up for a wrong through the expressive and communicative functions which tie it constitutively to the act of apologising. Consequently it is as mistaken to assess a rectificatory act principally in terms of how much it benefits its recipient as it is to assess a gift principally in terms of how much it cost.

The first prong of the assault on affirmative action trades on a one-sided conception of redress. It lulls us into the false assumption that redress for unjust discrimination is exhausted by compensation for the harm that discrimination caused, ${ }^{28}$ and then points out that affirmative action benefits some people who were not harmed at all by unjust discrimination and benefits those people who were harmed to an extent which generally fails to match the extent of the harm they suffered. I have explained why we must reject the false assumption on which this prong of the assault rests. There is, in addition to compensation for harm, another form of redress, rectification of a wrong. I have explained why affirmative action programmes have characteristics that suit them to being methods of making amends for unjust discrimination. I have also explained why, once we consider affirmative action as, at least in part, a method of rectification of unjust discrimination, there is no longer a legitimate expectation that victims of the same unjustly discriminatory policy should be benefited equally by a rectificatory affirmative action programme. Furthermore, I have explained why, given that unjust discrimination can be a harmless wrong, it is acceptable and to be expected that some beneficiaries of affirmative action should not have been harmed at all by unjust discrimination.

Insofar as an affirmative action policy is implemented in order to rectify an injustice, this goal places its own constraints on that policy's design. Only those who have been wronged ought to benefit from affirmative action as a form of amends-making. This may in practice translate into a minimum age for those who can benefit from the

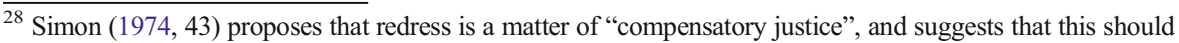
follow a "Proportionality Principle", according to which 'the strength of one's compensatory claim, and the quantity of compensation one is entitled to is, ceteris paribus, proportional to the degree of injury suffered'. He finds affirmative action wanting because it does not conform to the "Proportionality Principle". Similarly, Goldman $(1975,36)$ complains that with affirmative action 'there is in fact an inverse ratio established between past discrimination and present benefits', making affirmative action unfit as a means of redress. Cohen (2003a, 26) uses "compensation" and "redress" as equivalent terms and says what they refer to is deserved - in the context of U.S. racial discrimination - when "people ... have been hurt because of their race, damaged or deprived because they were black or brown'. Benatar $(2008,281-282)$ uses "rectification" and "compensation" interchangeably and assumes that if affirmative action is a mechanism of redress, it should benefit those most disadvantaged by past discrimination more than those "least disadvantaged by prior discrimination - those who received a good education despite discriminatory policies'.
} 
affirmative action policy, or a restriction of the scope of the policy to citizens of a certain country or residents of a certain region. Of course, when amends-making on a massive scale is called for, as with some of the worse injustices committed by states, a somewhat substantial margin of error may have to be tolerated. This margin will be more tolerable when there is a high chance that beneficiaries of affirmative action to whom rectification is not due were nonetheless harmed as a result of the injustice, so that, though amends may not be due to them directly, the advantages they receive through affirmative action can at least go some way towards compensating them adequately for this harm.

No one is likely to deny that the implementation of rectification on a large scale must be something of a messy process; and it is not for philosophy to speculate about how it should best be managed. But philosophy can contribute the conceptual point that, while adequate compensation ought to be carefully matched in quantity, and sometimes in quality, to each injured party's individual welfare loss, the constraints on adequate rectification do not dictate anything like this finely-tuned matching process. That is why we should grant that, considered solely as a means of compensation, affirmative action would generally be unacceptably clumsy, but maintain - contrary to the first prong of the assault on affirmative action - that it can be a fitting means of rectificatory redress for all that.

The third prong of the assault on affirmative action ("wrong reasons") trades on the same false assumption as the first prong.

This prong of the assault grants, for the sake of argument, that diversity with regard to the possession or non-possession of some characteristic (characteristic $C$ ) which does not itself render an applicant more qualified can bring benefits to an institution, those linked to it, or the wider community. (I will later briefly discuss what some of these benefits might be.)

It then considers two possibilities. The first possibility is that the first prong of the assault on affirmative action is successful, in which case affirmative action programmes cannot legitimately be introduced in order to make redress to victims of unjust discrimination. But if that is the case, says this prong of the assault, then affirmative action programmes certainly can't be introduced purely in order to achieve the benefits of $C$-diversity. Such consequentialist considerations, it claims, could not trump applicants' legitimate expectation of equal opportunities.

The second possibility is that (contrary to the first prong of the assault on affirmative action) affirmative action programmes at least sometimes are justifiable as ways of making redress to victims of unjust discrimination. But if that is the case, says this prong of the assault, then any benefits of $C$-diversity that ensue could only be happy by-products, since the decision to implement an affirmative action policy and the design of the affirmative action policy which is implemented could be justified only by their ability to compensate victims of unjust discrimination for the harm they suffered.

Even if it were granted that redress to victims of unjust discrimination would be exhausted by compensation for the harm they suffered, this prong of the assault would still not be fully convincing. This is because, even though, as we have seen, what counts as adequate compensation is very tightly controlled by the nature and extent of the harm which needs compensating, there is normally at least some room for choice as to the method of compensation. If in a particular case an affirmative action programme 
were an adequate way of compensating victims of discrimination for the harm they suffered, it is unlikely it would be the only adequate way possible. Surely, in such a case, it would be acceptable to choose affirmative action as the method of compensation rather than another, equally adequate, method of compensation, for the sake of the benefits of $C$-diversity, if these could reasonably be anticipated to outweigh the benefits of the other option. If so, surely it could be appropriate to criticise an institution, such as a state, which chose the other option rather than affirmative action, thus throwing away the benefits of $C$-diversity, no equivalent of which was to be had from the option selected. But, in that case, the choice of affirmative action as the method of compensation can be justifiable not just in virtue of its compensatory ability, but also in virtue of the benefits to be expected from $C$-diversity.

Though it insists that constraints of fairness would rule out introducing an affirmative action programme solely for the sake of the benefits of $C$-diversity, this prong of the assault on affirmative action does not claim that such constraints would rule out affirmative action for the sake of redress. That is fortunate, because this latter claim is far less plausible than the former claim. It is a commonplace of moral theory that constraints of fairness can restrict what means one may use to achieve desirable outcomes. But it is also generally recognised that individuals and institutions can, in the course of their business, acquire obligations which they must first discharge before they are at liberty to dispose of the goods and opportunities in their gift according to principles of pure distributive justice. For example, a dying man might have four friends to each of whom, all else being equal, distributive justice would say he should bequeath an equal share of his fortune. But if, in the course of his illness, he has borrowed $£ 2,000$ from one of those friends, then it is clear the dying man should first repay his debt, and only then endeavour to do what distributive justice demands given the allotment following his repayment. Incurring a financial debt is not the only way one can acquire an obligation of this kind. If one of his friends had done the dying man an extraordinary service in the past, it could also be appropriate for the man to do something for that friend, to express his gratitude, which would diminish the shares of his fortune that the other three friends ultimately received. The parallel between this obligation and the obligation to repay a loan is acknowledged in the colloquial phrase "a debt of gratitude". A further way in which one can acquire an obligation of this kind is by wronging somebody, and in this case the obligation one acquires is an obligation to make redress to the victim of one's wrong action. Though we don't speak of "a debt of redress", "a debt of compensation" or "a debt of amends", the obligations these made-up phrases refer to are as familiar to us as financial debts and debts of gratitude. ${ }^{29}$

When it comes to that part of redress due to a victim which is rectificatory (making amends for a wrong), there will, as we have already seen, generally be more scope for choice of the means of redress than with compensation. That is because what counts as adequate amends is, unlike what counts as adequate compensation, not tightly controlled by the nature and extent of the harm caused. Consequently, in cases where affirmative action would be one adequate means of rectification, it is even more likely than in cases where affirmative action would be an adequate means of compensation

\footnotetext{
${ }^{29}$ See Thomson 1973, 33-35. She notes that 'if we have wronged A, we owe him something: we should make amends, we should compensate him for the wrong done him' (35), but does not distinguish between rectification and compensation, using the expressions "compensate" and "make amends" interchangeably.
} 
that other acceptable options will exist. Should those other options not promise benefits comparable to the benefits of diversity to be expected as a result of an affirmative action programme, then surely it would be reasonable and acceptable to choose affirmative action as the method of making amends over those other options because of the superior consequences it will have. But if that is true then it can be reasonable and acceptable to implement an affirmative action programme (rather than another method of making amends) because of the beneficial consequences reasonably to be expected from it.

The second prong of the assault on affirmative action ("no benefits") denies that beneficial consequences are to be expected from the increase in diversity effected by affirmative action, or at least claims that these are neutralised or outweighed by the harmful consequences of affirmative action.

The chief beneficial effects on institutions, those professionally linked to them, or the wider community which are said to flow from an increase in diversity due to affirmative action include:

$(\alpha)$ Achievement of excellence. The presence of people with various different views and ways of thinking, springing from their different experiences and backgrounds, tends to promote innovation and creativity, which can lead to excellence in various fields of work and aid in the pursuit of truth in research. ${ }^{30}$

( $\beta$ ) Destruction of stereotypes. Working or studying alongside people of diverse backgrounds tends to disconfirm one's negative stereotypes about people of other backgrounds, thus increasing social harmony and understanding. ${ }^{31}$

$(\gamma)$ Role models. If in the past very few $C$-possessors have studied at particular institutions or done particular jobs, it tends to encourage other $C$-possessors to strive to achieve these goals if they are aware of $C$-possessors who have already done so. ${ }^{32}$

( $\delta$ ) Service delivery to communities. When $C$-possessors live in communities which are to some degree separate from those of non- $C$-possessors, it may in practice be important that a significant number of $C$-possessors acquire training and employment in fields such as law and medicine, as non- $C$-possessors who are lawyers or doctors may be less likely to practise in $C$-possessor communities. An increase in $C$-diversity in professions such as law and medicine can consequently tend to improve service delivery to $C$-possessor communities. ${ }^{33}$

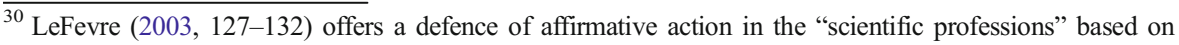
arguments that diversity of background and viewpoint makes scientific communities better able both to discover the truth and to avoid error. See Benatar 2012, 228-229, for a critical discussion of this justification for gender affirmative action; and see Benatar 2008a, 289-291, for a critical discussion of this justification for racial preference.

${ }^{31}$ LeFevre $(2003,125-126)$ briefly outlines and endorses a defence of affirmative action along these lines. For critical discussion of this justification for preferential policies see Benatar 2008a, 291-293; Benatar 2008b, $215-217$.

32 See Dworkin 1985, 299; Dworkin 2007, 486. For critical discussion of this justification for racial preference see Benatar 2008a, 293-295; Benatar 2008b, 217-218; Benatar 2012, 229-231.

${ }^{33}$ See Dworkin 1985, 299; Dworkin 2007, 486.
} 
It is also said that affirmative action can have a variety of harmful effects, chief among which are:

$(\varepsilon)$ Lowering standards. When the most qualified candidate for a place, position or contract is passed over in favour of another qualified candidate who is a $C$ possessor, there is a high chance that the tasks attached to that place, position or contract will be carried out to a less high standard than they would have been, had the most qualified candidate been selected. Thus preferential policies can tend to lead to a lowering of standards. ${ }^{34}$

(द) Reinforcement of stereotypes. When less qualified $C$-possessors are awarded places, positions or contracts, instead of more qualified non- $C$-possessors, the relative abilities of $C$-possessors and non- $C$-possessors in the resulting body of workers, trainees, students or contractors may unwarrantedly reinforce some people's stereotypes about $C$-possessors, thus reducing social harmony and understanding. 35

( $\eta$ Social division. When it is widely known that whether or not one possesses characteristic $C$ is sometimes decisive in determining whether one attains significant goods, this knowledge can make $C$-possessors and non- $C$-possessors see themselves as opposing groups competing with one another, rather than as all members of one society aiming at a common good. ${ }^{36}$

( $\theta$ ) Stigma. When it is widely known that an institution, or a number of institutions, gives $C$-possessors preference in recruiting or contracting decisions, this can lead people to assume that any $C$-possessor who gets a place, position or contract is less qualified or otherwise able than non- $C$-possessors who applied, and could not have succeeded without this extra leg up. This tends to create a stigma of inferiority which even exceptionally qualified and able $C$-possessors must battle against. $^{37}$

It has been claimed that diversity could not have both beneficial effect ( $\alpha$ ) (above) ("achievement of excellence") and beneficial effect ( $\beta$ ) (above) ("destruction of stereotypes"), because if - for whatever reason- $C$-possessors were different enough from non $C$-possessors in their views and thinking for beneficial effect $(\alpha)$ to ensue, then stereotypes concerning them would not be destroyed but confirmed, meaning beneficial effect $(\beta)$ did not ensue. ${ }^{38}$ However the most harmful stereotypes, and consequently those it would be most beneficial to destroy, have to do with the relative professional and intellectual ability of people from different groups; and it is perfectly possible to realise that an individual is as able as you are in some respect at the same time as acknowledging that_-perhaps because of their cultural background, or life

\footnotetext{
${ }^{34}$ See Cohen 2003a, 111, 135, 143-145; Benatar 2008a, 303-304. Sterba (2003b, 336-337) responds critically to the charge that affirmative action leads to lowering standards.

35 See Cohen 2003a, 110; Benatar 2008a, 292-293.

36 See Cohen 2003a, 164-170; Benatar 2008a, 302-303.

${ }^{37}$ See Hill 1991, 178; Cohen 2003a, 110. Cohen, discussing racial preference in the U.S.A., writes: 'An ethnic group given special favor by the community is marked as needing special favor-and the mark is borne prominently by every one of its members. Nasty racial stereotypes are reinforced, and the malicious imputation of inferiority is inescapable because it is tied to the color of skin' (110).

38 Benatar (2008a, 291) writes that the 'destruction of stereotypes' argument ... denies the very thing that the 'pursuit of truth' argument assumes - namely that racial diversity (significantly) enhances opinion diversity'.
} 
experiences - they have come up with an idea or an approach to a problem which you would never have thought of yourself. Therefore it is false to say that beneficial effect $(\alpha)$ and beneficial effect $(\beta)$ could not both ensue from an increase in diversity together.

Otherwise it is difficult to say very much which applies across the board in response to the second prong of the assault on affirmative action. It is certainly plausible to think that each of the various effects listed above would indeed ensue in some instance of affirmative action. It seems much less plausible to say that the harmful effects $(\alpha)-(\delta)$ listed above would ensue, and either neutralise or outweigh the beneficial effects $(\varepsilon)-(\theta)$ listed above, in every instance of affirmative action. From what I have said already in response to the first and third prongs of the assault on affirmative action, it follows that an affirmative action policy may sometimes legitimately be implemented even if its harmful effects outweigh its beneficial effects, since it may still constitute a fitting, or indeed the most fitting, way of making amends for unjust discrimination - though of course this is less likely to be the case if it is the beneficiaries of the affirmative action policy themselves who bear the brunt of its harmful effects. It would be desirable to do empirical research in order to establish how beneficial or harmful, overall, a prospective affirmative action programme is likely to be, because such research could rightly influence the decision whether to make amends for unjust discrimination through affirmative action or by some other means. However, I do not claim that the benefits to be expected from an increase in diversity could justify an affirmative action programme on their own.

Critics of affirmative action claim that its defenders who appeal to the benefits of diversity when justifying affirmative action are bound by consistency to endorse further policies which they would likely prefer to oppose. For example, it has been claimed that anyone who supports affirmative action because of beneficial effect ( $\alpha$ ) (above) ("achievement of excellence") must also endorse preferential hiring of religious fundamentalists in most professions, and the preferential appointment of political conservatives in university humanities faculties. ${ }^{39}$ Both these policies would add to the diversity of viewpoints represented in those professions or institutions, so it is inconsistent- say the critics - to oppose them. Or else critics of affirmative action point out that to achieve most of the beneficial effects listed above it may well only be necessary for the proportion of $C$-possessors in a body of workers, students or contractors to rise very slightly above zero. Such a very slight increase might well be enough to trigger innovation through viewpoint diversity, destroy negative stereotypes and provide the necessary role models to the wider community. But then - say the critics - it would not be justifiable to introduce an affirmative action programme which effected anything more than this slight increase in the proportion of $C$-possessors. ${ }^{40}$

Someone who defended affirmative action solely on the basis of the benefits of diversity might be vulnerable to charges of inconsistency like these. But what I have argued is that, when choosing how to make amends to $C$-possessors for past $C$ discrimination, the benefits to be anticipated from $C$-diversity may justify the decision to rectify that injustice by means of affirmative action rather than by other means. Thus it is already fixed by the goal of making amends to $C$-possessors that $C$-possessors, not others, will be the ones given preference, should a preferential recruitment or

\footnotetext{
${ }^{39}$ See Sher 1999, 99-100; Benatar 2008a, 289-290; Benatar 2008b, 214-215; Benatar 2012, 228-229.

${ }^{40}$ See Benatar 2008a, 290-292; 229-230.
} 
contracting policy be chosen as the means of rectification. Unless there is an equal need to make amends to the other groups mentioned - religious fundamentalists and political conservatives - it is not true that consistency demands affirmative action policies for these groups just because such policies would have some of the same benefits. ${ }^{41}$ Equally, if the role of an appeal to the benefits of diversity is limited to justifying the choice of affirmative action over other methods of rectification, then it is not true that the preferential policy must be calibrated to produce only that level of $C$-diversity which will have beneficial effects, and nothing more. That is because once the justificatory power of an appeal to the benefits of diversity is exhausted, there still remains the standing justificatory power of the requirement that amends be made to a wronged party, on which the former was in any case always dependent.

It is also worth noting at this stage that increasing diversity may in some instances itself constitute a form of redress. This is because if someone is the sole $C$-possessor, or one of very few $C$-possessors, in an organisation, this can be a difficult situation which is disadvantageous to them in various ways. If this disadvantageous situation came about due to the organisation's unjust discrimination against $C$-possessors in the recent past, this means it is a case of harm due to injustice which would warrant compensation. Increasing $C$-diversity in the organisation would constitute at least the beginnings of compensation, since it would alleviate the disadvantageous position of the $C$-possessor in question. ${ }^{42}$ This consideration could sometimes be a further reason why an organisation should choose a policy of $C$-preference as its way of making amends to $C$-possessors.

Affirmative action is not always the best way for an institution to make redress for unjust discrimination. But the fact that preferential recruiting or contracting policies can be a fitting way of making amends for-and not just a means of compensating the harm caused by - unjust discrimination enlarges the class of cases where affirmative action is an appropriate means of redress far beyond what its critics have claimed. The philosophical assault on affirmative action which portrays is as structurally unsuited to providing redress for unjust discrimination is fatally flawed because it relies on an impoverished conception of redress.

Defenders of affirmative action have been accused of flitting opportunistically between incompatible arguments for policies of preference. However, it is untrue to say that justifications of affirmative action which invoke the benefits of diversity are incompatible with justifications of it which invoke the necessity of redress, and it is certainly untrue that the benefits of diversity could never play a decisive role in justifying a preferential policy. The benefits to be expected from diversity can legitimately lead an institution to choose a preferential policy, and not any one of a number of other options, as its way of making amends for unjust discrimination.

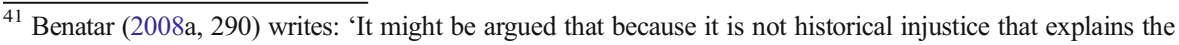
under-representation of these groups [sc. conservatives and religious fundamentalists] in universities, they (unlike 'blacks', for example) are not eligible for affirmative action. However, this response constitutes an abandonment of the diversity argument in favour of a rectification argument for affirmative action. It is no longer an argument about diversity being necessary to foster the pursuit of truth, but is instead an argument about rectifying injustice.' Benatar's reasoning rests on a false dichotomy. Justifying affirmative action by appeal to diversity's tendency to foster the pursuit of truth is not incompatible with justifying it as a way of making redress for injustice. The tendency of diversity to foster the pursuit of truth can justify choosing affirmative action (rather than some other means of redress) as one's way of making amends to people one has unjustly discriminated against in the past.

${ }^{42}$ I am indebted to an anonymous reviewer for this journal who raised this point.
} 
Empirical research, and not just philosophy, will be relevant to determining when such a choice is the right one.

Open Access This article is distributed under the terms of the Creative Commons Attribution License which permits any use, distribution, and reproduction in any medium, provided the original author(s) and the source are credited.

\section{References}

Benatar, D. (2008a). 'Justice, Diversity and Racial Preference: A Critique of Affirmative Action'. South African Law Journal, 125, 2.

Benatar, D. (2008b). Diversity Limited. In L. Thomas (Ed.)., Contemporary debates in social philosophy. Malden: Blackwell.

Benatar, D. (2012). The Second Sexism: Discrimination Against Men and Boys. Chichester: Wiley-Blackwell. Bloch, G. (2009). The Toxic Mix: What's Wrong with South Africa's Schools and How to Fix It. Cape Town: Tafelberg.

Bovens, L. (2008). Apologies'. Proceedings of the Aristotelian Society, 108, 3.

Bovens, L. (2009). 'Must I Be Forgiven?'. Analysis, 69, 2.

Boxill, B. R. (1972). The Morality of Reparation. In S. M. Cahn (Ed.), The affirmative action debate (pp. 107114). New York: Routledge.

Cohen, C. (2003a). Section One: Why Race Preference is Wrong and Bad. In C. Cohen \& J. P. Sterba (Eds.)., Affirmative action and racial preference: a debate. New York: Oxford University Press.

Cohen, C. (2003b). Section Three: Reply to James Sterba. In C. Cohen \& J. P. Sterba (Eds.)., Affirmative action and racial preference: a debate. New York: Oxford University Press.

Davis, P. (2002). 'On Apologies'. Journal of Applied Philosophy, 19, 2.

Dworkin, R. (1976). DeFunis v. Sweatt. In M. Cohen, T. Nagel \& T. Scanlon (Eds.)., Equality and preferential treatment. Princeton: Princeton University Press.

Dworkin, R. (1977). Taking rights seriously. Duckworth: Guildford \& King's Lynn.

Dworkin, R. (1985). Bakke's Case: Are Quotas Unfair?. In B. Boxill (Ed.), Race and racism. Oxford: Oxford University Press.

Dworkin, R. (2007). The Rights of Allan Bakke. In H. LaFollette (Ed.)., Ethics in practice: an anthology. Malden: Blackwell.

Goldman, A. H. (1975). Reparations to Individuals or Groups? In S. M. Cahn (Ed.), The affirmative action debate (pp. 35-38). New York: Routledge.

Goldman, A. H. (1976). Affirmative Action. In M. Cohen, T. Nagel \& T. Scanlon (Eds.)., Equality and preferential treatment. Princeton: Princeton University Press.

Gumede, W. (2007). Thabo Mbeki and the battle for the soul of the ANC. London: Zed Books.

Hill, T. E., Jr. (1991). The Message of Affirmative Action. In S. M. Cahn (Ed.), The affirmative action debate (pp. 169-192). New York: Routledge.

Jones, M. (1995). The limits of liberty: American history 1607-1992 (2nd ed.). Oxford: Oxford University Press.

LeFevre, J. (2003). 'The Value of Diversity: A Justification of Affirmative Action'. Journal of Social Philosophy, 34, 1.

Mbeki, M. (2009). Architects of poverty: why African capitalism needs changing. Johannesburg: Picador Africa.

Nozick, R. (1974). Anarchy, State, and Utopia. Malden: Blackwell.

Pojman, L. (2007). Against Affirmative Action. In H. LaFollette (Ed.)., Ethics in practice: an anthology. Malden: Blackwell.

Sandel, M. (2012). What money can't buy: the moral limits of markets. London: Allen Lane.

Sher, G. (1975). Justifying Reverse Discrimination in Employment. In M. Cohen, T. Nagel \& T. Scanlon (Eds.)., Equality and preferential treatment. Princeton: Princeton University Press.

Sher, G. (1999). 'Diversity'. Philosophy and Public Affairs, 28, 2.

Simon, R. (1974). Preferential Hiring: A Reply to Judith Jarvis Thomson. In M. Cohen, T. Nagel \& T. Scanlon (Eds.)., Equality and preferential treatment. Princeton: Princeton University Press.

Sterba, J. P. (2003a). Section Two: Defending Affirmative Action, Defending Preferences. In C. Cohen \& J. P. Sterba (Eds.)., Affirmative action and racial preference: a debate. New York: Oxford University Press. 
Sterba, J. P. (2003b). Section Four: Reply to Carl Cohen. In C. Cohen \& J. P. Sterba (Eds.)., Affirmative action and racial preference: a debate. New York: Oxford University Press.

Swinburne, R. (1989). Responsibility and atonement. Oxford: Clarendon.

Terreblanche, S. (2012). Lost in transformation: South Africa's search for a new future since 1986. Johannesburg: KMM.

Thompson, L. (2000). A history of South Africa (3rd ed.). New Haven: Yale University Press.

Thomson, J. J. (1973). Preferential Hiring. In M. Cohen, T. Nagel \& T. Scanlon (Eds.)., Equality and preferential treatment. Princeton: Princeton University Press.

Tindall, G., \& Shi, D. (1997). America: a narrative history. Brief (4th ed.). New York: Norton.

Wolff, J. (2011). Ethics and public policy: a philosophical inquiry. London: Routledge. 